\title{
Atendimento Psicológico e Direção Espiritual: Semelhanças, Diferenças, Integrações e... Confusões ${ }^{1}$
}

\author{
Mario Aletti ${ }^{2}$ \\ Università Cattolica di Milano
}

\begin{abstract}
RESUMO - A psicoterapia e o aconselhamento espiritual têm algumas características comuns: ambos são relações nascidas de um pedido de ajuda e seu escopo se refere ao crescimento gradual da pessoa. Porém muitas são também as diferenças, evidentes quando a referência é a psicoterapia psicanalítica. Esta é uma relação funcional e temporária, livre e assimétrica; prevê um setting preciso e a observância rigorosa das regras de abstinência e de neutralidade. Essas características estão apenas parcialmente presentes na direção espiritual que, além disso, difere também pela finalidade (salvação vs. bem-estar psíquico) e pelos meios (diálogo consciente vs. interpretação dos desejos inconscientes). A interação entre as duas modalidades de ajuda (por exemplo, a psicoterapia desenvolvida por um profissional religioso) oferece algumas possibilidades de integração, mas também muitos riscos de confusão e de sobreposição de papéis.
\end{abstract}

Palavras-chave: psicoterapia psicanalítica; direção espiritual; aconselhamento religioso; neutralidade.

\section{Psychological Assistance and Religious Direction: Analogies, Differences, Integrations and Confusions}

\begin{abstract}
Psychotherapy and religious counselling have some common features: both are relations based on a help request and their intent is a gradual and personal growth. However, the differences are many and they become clearly visible with reference to the psychoanalytic psychotherapy. Psychoanalytic psychotherapy is a functional and temporary relationship, it is also free and asymmetric; it supposes a specific setting and an abstinence and neutrality rules compliance. These features are just partially present in the spiritual direction which, moreover, there is another purpose (salvation vs psychical well-being) and other means (conscious dialogue vs interpretation of unconscious desires). The interaction between these two help modalities (e.g. the psychotherapy pursued by a religious professional) gives some possible integration, but also many risks of confusion and overlapping roles.
\end{abstract}

Key words: psychoanalytic psychotherapy; spiritual direction; religious counselling; neutrality.

\section{Objetivos, Opções, Limites do Atendimento}

Para uma primeira aproximação a uma temática complexa como a que nos propomos, seria uma boa aquisição a que levasse a identificar alguns pontos de confronto (semelhanças e diferenças), a indicar as possíveis interações úteis e a assinalar as conseqüências de apressadas contaminações, entre atendimento psicológico e acompanhamento espiritual. No entanto, ciente de que "onde se chega" é também função de "de onde se parte", gostaria de explicitar, a modo de premissa, algumas suposições de minha parte e os conseqüentes limites de minha intervenção.

No nível metodológico, minha opção é, em primeiro lugar, por uma comunicação pragmática e eficaz, voltada para a reflexão de alguns aspectos do que já se faz, a fim de oferecer estímulos ao debate e ao confronto. No que diz respeito a minha intervenção, isso se traduz no intento de comunicar algum fragmento de conhecimento derivado de uma prática psicoterapêutica efetivamente exercida, confrontando-a com alguns princípios da psicodinâmica. Para sublinhar as valências e a parcialidade de um tal testemunho, mas também o inevitável coeficiente interpessoal de toda relação terapêutica, utilizarei o discurso em primeira pessoa.

1 Tradução, do italiano, de Geraldo José de Paiva.

2 Endereço: Dip.to di Psicologia, Università Cattolica, 20123, Milano, Italia. E-mail:mario.aletti@iol.it
O privilégio concedido à praxe (não uma prática qualquer, mas aquela guiada pela reflexão crítica) comporta a renúncia a demorar-nos no grande debate, hoje particularmente aceso em âmbito anglófono e germânico, acerca das oportunidades, modalidades, significado do acompanhamento espiritual e, mais em geral, acerca da complexidade das relações que entrelaçam pastoral e psicologia ${ }^{3}$.

Certamente não falarei de como se articula uma direção espiritual, de seus fins, de suas diversas modalidades de intervenção. Essas são assinaladas e, às vezes, esclarecidas (outras, confundidas) também por diferentes denominações: discernimento e/ou acompanhamento vocacional, direção espiritual, counselling, diálogo pastoral ou também psicoterapia pastoral... As diversas formas de acompanhamento espiritual variam em função do objetivo, do destinatário e de seu nível de crescimento espiritual e também da pessoa que assume o papel de guia.

$\mathrm{O}$ ponto de vista aqui privilegiado é principalmente o de quem fornece a ajuda, não tanto do destinatário-fruidor, embora, certamente, muito se pudesse dizer também do ponto de vista de quem solicita a ajuda. Por exemplo, será diverso o discernimento e o acompanhamento vocacional da direção

3 Para um primeiro reconhecimento crítico e uma abertura para algumas novas perspectivas de tal diálogo, do ponto de vista da teologia pastoral, veja-se o ensaio de Seveso (2003). 
de um leigo cristão empenhado ou de uma pessoa não crente mas "em busca"; ainda mais diferente será a tarefa de guia exercida por um "padre" prior ou por uma "madre" abadessa em um mosteiro, onde essas figuras são chamadas a reassumir em si mesmas os papéis típicos, seja da figura paterna, seja da materna (autoridade, ternura, para resumir esquematicamente). Pense-se ainda na especificidade da figura do confessor e/ou diretor espiritual designado em um mosteiro de clausura, onde a liberdade de escolha é, de fato, limitada.

Não deveriam ser, tampouco, descuradas as variáveis introduzidas pela própria personalidade do guia/diretor, por sua sensibilidade e por sua sintonia, seja com a pessoa que o procura, seja com a tarefa que lhe foi delegada e, sobretudo, pela sua experiência pessoal de vida espiritual. Pessoalmente, recordo com simpatia um velho diretor espiritual de olhar límpido, sereno, de quem atravessou a vida amando-a e ainda a ama, em si mesmo e nos outros. Ao contrário, que testemunho, que mediação, pode ser a pessoa do Diretor Espiritual severo e duro, que talvez te escute em um cantinho escuro e frio? Às vezes sairia espontânea a pergunta: "Mas porque você está tão triste? Brigou com o mundo inteiro? Talvez a Boa Nova da Redenção de Cristo chegou para todos, menos para você?" Naturalmente, a mesma coisa vale também para o psicanalista: não me confio, e não indico nunca, um psicanalista triste, com um horizonte de vida desconfortável, depressivo ou apenas com um semblante pouco sereno.

Perante tanta variedade, vou limitar-me a um discurso geral, aplicável a todas as situações individuais, falando de estruturas, processos psíquicos e, sobretudo, modalidades relacionais envolvidas e operativas em toda forma de diálogo pastoral, e em suas diversas funções ${ }^{4}$.

Naturalmente, o ponto de vista da psicologia é unilateral (não partidário, mas certamente parcial) e, como tal, apela, na prática da vida cotidiana, à integração com outros pontos de vista. O homem é uno e unitário. Põe-se por inteiro em jogo em toda relação -também naquela de direção espiritual não menos que na relação com Deus -, quer dizer, sua identidade pessoal e a complexa história de seu estruturar-se. Na realidade, no homem "real", as distinções entre psique e espírito, corpo e alma e, internamente à psique, entre cérebro e mente, natureza e cultura, ontogênese e filogênese são tão metodologicamente úteis quanto substancialmente redutoras. A chamada à integração da personalidade, no sujeito real, diz também da continuidade entre "sadio" e "doente". O conceito de saúde tem uma matriz comparativa e processual, que não exclui distorções e desvios patológicos, e isso inclui também o estado doentio. Isso é tanto mais verdade quando se trata da psique, onde o bom funcionamento é variável, dependente de tantos fatores (do biológico ao cultural, dos mecanismos inconscientes às escolhas conscientes...) que se entrelaçam na vasta e variadíssima gama de comportamentos psicologicamente "sadios", isto é, funcionais para o equilíbrio psicodinâmico da pessoa. A patologia consiste na incapacidade parcial ou total, persistente ou temporária, de resolver conflitos psicológicos que pessoas "normais" estão em condição de elaborar sem excessivo dispêndio de energias (critério econômico).

4 Vinte anos atrás, André Godin, mestre de psicologia da religião e também de vida espiritual, indicava a necessidade de harmonizar, no diálogo pastoral, quatro funções: acolhida, direção, mediação, discernimento. Veja-se Godin (1987).
Tampouco se deve temer que uma perspectiva clínica induza uma visão preconceituosa do homem e de sua psique ("doente"): porque exatamente o que é observado dessa forma é o homem concreto, real, posicionado numa linha de continuidade entre os pólos abstratos da saúde e da doença. A psicologia clínica (e a psicologia clínica da religião, especificamente) aprendeu que estruturas, processos, mecanismos psíquicos se manifestam de modo igualmente fácil tanto em seu "mau funcionamento" como na "normalidade" funcional. Como acontece, dizia Freud, com o cristal mineral que, despedaçando-se segundo linhas de clivagem que já estavam presente na sua estrutura cristalina, revela seus segredos internos e constitutivos 5 .

O ponto de vista aqui adotado é o da prática clínica de psicoterapia psicanalítica. De uma prática, a saber, entendida como lugar do surgimento da verdade do sujeito ao próprio sujeito, mediante a palavra trocada entre duas pessoas em uma situação de profunda tensão relacional (transferência e contratransferência). Trata-se de uma "cura", o que significa que não sequiestra a atenção para a gestão de sintomas patológicos e/ou para a recuperação de competências mentais fragmentárias e segmentadas; que não usa o psicofármaco em função anestésica, como faz aquela parte da psiquiatria que se reduz a encefalolatria e com o fármaco tende a tornar muda a dor e, ao mesmo tempo, a cortar a palavra ao paciente... Se uma irmã num mosteiro de estrita clausura sofre de graves formas de claustrofobia, alguma coisa certamente isso quer dizer acerca de sua escolha de vida e acerca de seu modo de interpretar sua história de sofrimento. Isolar o sintoma do conjunto da história do sujeito e calá-lo com o psicofármaco, permanece um gesto "restaurador" isolado em si, que fala da recusa a confrontar-se, a escutar e compreender. Ao contrário, a terapia a que me refiro propõe-se como compreensão da orientação pessoal, representacional e relacional do sujeito-pessoa na complexidade de seus componentes: corpóreos, neurobiológicos, emotivo-afetivos, motivacionais, intelectuais, sociais, culturais... seguindo-o na sua história e em seu vir-a-ser mediante processos que não são sempre harmoniosos e sincrônicos, mas são atravessados por dificuldades, conflitos e crises, de soluções não unívocas e não previsíveis. Daí nasce uma perspectiva clínica, um modo de olhar o sujeito que supõe ficar "inclinado" sobre ele, dirigindo a atenção para suas características específicas, idiossincráticas, não contidas dentro das gaiolas teóricas dos modelos diagnósticos psicológicos ou psiquiátricos.

Uma tal perspectiva clínica torna possível, mesmo de fora da prática psicoterapêutica, reconhecer a complexidade da "formação" da identidade pessoal ao longo da história do sujeito e fornece referências para avaliar a ontogênese psíquica do sujeito e a adequação dos atendimentos de direção e de acompanhamento (eventualmente, espiritual), sugerindo alguma consciência a mais acerca das modalidades de um trabalho que, em todo o caso - é bom recordar -, tem sido

5 Bem conhecemos a noção de que a patologia, tornando as coisas maiores e mais toscas, pode atrair nossa atenção para condições normais que de outro modo nos escapariam. Onde ela mostra uma brecha ou uma rachadura, ali pode normalmente estar presente uma articulação. Se atirarmos ao chão um cristal, ele se parte, mas não em pedaços ao acaso. Esse se desfaz, segundo linhas de clivagem, em fragmentos cujos limites, embora fossem invisíveis, estavam predeterminados pela estrutura do cristal (Freud, 1932/1996, p. 64). 
sempre praticado, também antes do esclarecimento trazido pelas disciplinas psicológicas.

Essa última chamada pretende sublinhar que a direção espiritual é modalidade relacional antiga na história do homem, bem anterior à teorização psicológica. Mas em geral, todos temos uma psique e todos utilizamos modalidades psicológicas de comunicação em nosso relacionamento com os outros, mesmo se nem todos temos disso o conhecimento reflexo e sistemático sintetizado (e esquematizado, vale dizer empobrecido) da psicologia científica. Para fazer uma comparação, o homem desde sempre navega os mares, aproveitando a força dos ventos, muito antes de conhecer as leis da dinâmica eólica. Mas o conhecimento reflexo e consciente habilita a uma conscientização daquilo que já acontece em nós e por nosso intermédio, também sem nosso conhecimento, no nosso relacionamento, profissional ou pessoal, com o outro. Hoje navegamos melhor do que no passado, não porque bússola, anemômetro e navegador por satélite mudam a força dos ventos... mas porque podemos fazer deles um uso mais consciente, graças aos conhecimentos, seja da meteorologia, seja da dinâmica dos ventos.

Procurarei articular o discurso a partir de uma dupla perspectiva: uma, que chamarei ad intra, voltada para a elucidação de alguns aspectos psicodinâmicos no interior da vida espiritual e de seu acompanhamento e uma perspectiva ad extra, que sugerirá pontos de confronto (semelhanças, diferenças, interações) com o atendimento psicológico.

\section{Aspectos Psicodinâmicos da Vida Espiritual}

Proponho aqui só algumas deixas para reflexão, selecionadas com base em sua funcionalidade para o discurso sucessivo de confronto entre as duas relações de ajuda: a psicológica e a espiritual.

\section{Premissa: tudo é psíquico, o psíquico não é tudo}

O fundamento de uma leitura psicológica da vida espiritual está em seu pleno enraizamento nas dinâmicas humanas. Nesse sentido, enraizado quer dizer também encarnado, impresso/expresso na unidade corpo-cérebro-mente ${ }^{6}$.

Tudo o que é humano é psíquico. Vale também para a religião e para a vida espiritual, como para toda experiência humana que tudo é psíquico, embora o psíquico não seja tudo. Porque a psique é mediação entre o biológico e o cultural. Naturalmente, na religião existem outros fatores: sociais, históricos, lingüísticos, teológicos, filosóficos e certamente, para o crente, em sua relação com Deus, existe um fator único, específico e imprescindível: a graça divina e o encontro pessoal com Deus que se revela e doa e, mediante essa relação, age no coração do homem. Mas também esse encontro com Deus deve ser na medida do homem, compreensível ao homem, passar através das dinâmicas da psique humana e, destaco, não menos as inconscientes do que as conscientes ${ }^{7}$.

6 Para um enquadramento crítico dessa questão, veja-se o volume organizado por Aletti, Fagnani e Rossi (2006).

7 Insisto em que o inconsciente não é uma espécie de homunculus que controla o sujeito e/ou anula consciência e liberdade do sujeito - segundo superados estilos caricaturais antigamente utilizados por alguns opositores da psicanálise. Útil, além de mais adequado, seria pensar no inconsciente
Naturalmente, a psicologia, de seu canto, pode reconhecer na mente do crente apenas as pegadas e o desejo de Deus, não a realidade daquele que as deixa. A psicologia permite colher os significados e as valências psicológicas dos símbolos, crenças e ritos religiosos. Mas, em razão de seus instrumentos de pesquisa, a psicologia não pode jamais verificar a existência da graça de Deus nem vê-la em obra no homem, nem, ao contrário, reconhecer na conduta humana a ação do Maligno. O que transcende a observação empírica não pode ser para a psicologia nem objeto de investigação, nem critério de explicação do comportamento humano. Mas o psicólogo não pode prescindir da convicção subjetiva do crente: isto é, do fato, observável empiricamente, de que esse sabe que Deus opera nele e essa convicção orienta também seu relacionamento com Deus, seu modo de ser religioso. Certamente, por exemplo, ter fé no Deus de Jesus Cristo é coisa bem diversa (também psicologicamente diversa) de uma genérica crença numa força primordial que origina o mundo.

\section{A mente representacional}

Nós conhecemos por meio de nossas representações mentais; propriamente, conhecemos nossas representações dos "objetos", e não os objetos. Assim acontece desde o objeto primário de amor, a mãe. A criança não conhece propriamente a mãe, mas sua relação com ela. Nessa perspectiva estrutural e relacional do indivíduo, Donald Winnicott podia propor um de seus célebres paradoxos: "A criança cria a mãe que encontra" (vale dizer: aquela mulher já está lá, mas não é "a mãe" da criança enquanto a criança não entra em relação com ela).

É importante, nesse ponto, ter presente que a representação psíquica não é um conceito, nem uma imagem, nem um símbolo. A representação psíquica de um objeto é um conjunto organizado de processos de memória, governado pelo princípio econômico do equilíbrio psicodinâmico, que resulta de um conjunto de condições, das quais muitas fogem à consciência do sujeito e algumas estão ancoradas em experiências "arcaicas" relativas à consciência: corpóreas, neurobiológicas, proprioceptivas, sensoriais. Não se pretende excluir os componentes conscientes, mas apenas sublinhar que esses são um surgimento posterior ao longo da evolução do sujeito e na estruturação dos posicionamentos do indivíduo. Esse enraizamento profundo vale para qualquer experiência humana e, por isso, também para a experiência religiosa. Certamente não a esgota, ao contrário, dela é apenas uma pré-condição. Mas, em consideração do fato de que é vezes demais escotomizada, pretendo sublinhá-la, com consciente unilateralidade. Também para denunciar a contradição de uma certa espiritualidade que, enquanto exalta o corpo como manifestação da glória divina, tende, na realidade, a renegá-lo rumo a uma pretensa espiritualização, que parece perseguir como próprio ideal o de uma alma sem corpo e de uma figuração religiosa sem representação mental. Aqui, ao contrário, queremos lembrar que nossa relação com Deus e "nossa religião" são também funções de experiências emotivas primárias que retrocedem até o contato físico com as

não como substantivo que se refira a uma "coisa", mas como adjetivo, qualificador de alguns aspectos da vida psíquica. Sublinhar seus componentes "inconscientes" quer dizer recordar que existem mais coisas em nossa psique do que nossa consciência atual pode conhecer. 
pessoas que de nós cuidaram nos primeiros meses de vida. O mesmo Winnicott - é bom recordá-lo, grande pediatra, além de psicanalista -, chamado a fazer uma conferência sobre a evangelização na família, surpreendeu seu auditório falando quase exclusivamente dos cuidados pré-verbais, a partir da importância decisiva do modo como a criança é segurada no braço e sustentando que é só em continuidade com a experiência pré-verbal da "confiabilidade humana", colhida no sentir-se abraçado e protegido, que a criança estará em situação de aproximar-se do conceitos de "braços eternos" de Deus (Winnicott, 1996, p. 116)

Assim, para mim, a religião é também minha avó. O terço com que pegava no sono em seus joelhos à noitinha e a visita junto com ela ao cemitério; a avó que, perto de morrer, falando de sua sepultura, dizia: "Não gastem dinheiro com meu funeral: eu estarei já do outro lado...”. De certo, a seguir, para estruturar a "minha" religiosidade, entraram em jogo também as orações junto a meus pais, o catecismo na paróquia e, mais tarde, as interrogações existenciais e as respostas encontradas na Palavra de Deus, as figuras dos sacerdotes encontrados, o estudo da teologia, a celebração litúrgica e sacramental e também o estudo dos dinamismos psíquicos mediante os quais se forma uma certa representação de Deus e não outra... Tudo isso contribuiu ao magma inconsciente representacional sobre o qual eu construí, gradualmente, a minha imagem de Deus, a minha teologia pessoal. Mas ocorre recordar que o pensamento consciente sobre Deus, a imagem que dele fazemos, nosso teologar intelectual e emotivo passa também pela representação inconsciente. E, por exemplo, quando vejo uma criança na igreja com o avô, em mim se reativam experiências profundas do passado que me fazem sentir mais vizinho a Deus.

A fé em um Deus não visível se ancora numa representação de Deus que o torne perceptível pelo homem. O nome de Deus é oferecido pela cultura, mas passa através do filtro da representação mental pessoal. Ecoando ainda uma vez Winnicott, diria que o crente "re-cria" a fé que "encontra".

Creio que se possa dar, agora, por adquirido que, para poder falar de Deus, para relacionar-nos com Ele, devemos fazer dele uma representação, que tem a função de mediação psíquica. Assim, quando digo que Deus é Pai, ativo esquemas representacionais que provêm: da valência simbólica intrínseca à figura paterna; da cultura, pela qual a expressão é mediada; e da apropriação pessoal da figura paterna, mediante as representações mentais, da infância e atuais.

A psicologia da religião mais perspicaz fala de figura paterna, não de conceito de pai, e Antoine Vergote argumenta que as características da figura paterna tornaram possível a Jesus tomar o termo humano para articular a própria relação com Deus, quando, para a reflexão filosófica, o conceito abstrato de pai não seria outra coisa que uma metáfora demasiado humana, a ser superada bem depressa (Vergote, 2006). A figura do pai se coloca dentro da família, lugar onde se entrecruzam a ordem biológica e a ordem cultural, transmissão da vida pela dualidade sexual e instauração de uma relacionalidade absolutamente privilegiada de amor fecundo. Em conseqüência de sua dupla pertença à ordem biológica e à cultural, a paternidade tem um sentido universal e ao mesmo tempo específico com base nas determinações histórico-culturais e nas significações pessoais que adquire para cada indivíduo. A paternidade assume, assim, também uma valência normativa que estrutura a diversidade, o desejo, a lei, o amor, a generatividade.

\section{Das representações mentais à maturação religiosa}

A incidência de processos inconscientes e em particular das representações das figuras parentais na estruturação do posicionamento de uma pessoa em relação a Deus foi evidenciada por Ana-María Rizzuto em um volume, alicerçado na prática clínica e teoricamente muito bem argumentado, que estuda a formação, o uso e a transformação das representações de Deus ao longo de todo o ciclo de vida (Rizzuto, 1979). Rizzuto mostra como a representação objetal de Deus, que se forma inicialmente na infância, conhece uma história e uma transformação dinâmica. A isso alude o título do volume $O$ nascimento do Deus "vivo".

A representação de Deus é uma realidade composta e sobredeterminada: para ela concorrem, em interação dinâmica, as relações com os objetos primários, a situação edípica e o gênero sexual a partir do qual ela é vivida, as características pessoais dos pais e das modalidades da interação real entre eles e a criança, a experiência dos irmãos, o ambiente sóciocultural, e também circunstâncias específicas e individuais que podem acompanhar o momento em que a representação se forma. Se a representação de Deus está profundamente ancorada nas representações de mãe e pai, o crente maduro está consciente de que a linguagem da fé é caracterizada por um excesso de sentido que se prolonga para além dos sinais. A maturidade religiosa inclui um progressivo distanciar-se e diferenciar-se da imagem de Deus, de suas fontes originais, num percurso de maturação (nunca concluído) do desejo, que permite a passagem "do ídolo ao ícone". Isso pode acontecer no homem de fé, com o estímulo da meditação, da oração, do encontro com o Deus vivo por meio da palavra com que Ele se revela ao homem e mediante mediações eclesiais, e não em último lugar a direção espiritual.

Mais complexa é a questão de como e em que condições se realiza uma transformação profunda da representação inconsciente em que se radica a imagem de Deus. Rizzuto faz referência a eventos importantes da experiência relacional, possíveis ao longo de todo o ciclo da vida, que incidam e reestruturem a representação do self, dos objetos primários e de seu relacionar-se dialético. Certamente isso é possível mediante as modificações intrapsíquicas e relacionais profundas que se podem verificar no curso de uma análise; se é possível instaurar um relacionamento maduro com os próprios genitores, será possível também uma representação de Deus não infantilmente ligada à nostalgia do pai. De outra parte, se a transformação da representação de Deus supõe uma reestruturação de memórias compostas por múltiplos níveis, em uma gradação que vai do visceral ao conceitual, coloca-se a questão da possibilidade, da eficácia, dos percursos e dos êxitos dos estímulos conscientes (suplemento de conhecimentos religiosos, participação em ritos coletivos, inserção numa cultura ricamente religiosa, escuta do Magistério e da Tradição, direção espiritual, etc.) relativamente a essa mudança profunda. E, a seguir, poder-se-ia perguntar se as transformações eventualmente verificadas devem ser reduzidas à força motivacional e transformadora interna ao 
sistema simbólico religioso (conteúdo da mensagem) ou à experiência relacional, que implica movimentos transferenciais e contratransferenciais, conexa com o encontro interpessoal, mediadora da mensagem (no caso que nos interessa, a pessoa do diretor espiritual). É claro que isso levanta muitas interrogações (e algumas perspectivas) sobre os níveis a que se orienta a ação pastoral e, no caso específico, o acompanhamento espiritual.

\section{Para um confronto entre atendimento psicológico e acompanhamento espiritual}

De imediato, uma chamada a algumas suposições preliminares (de certo modo, arbitrárias, mas funcionais para o confronto), já em parte antecipadas. Com o termo sintético de acompanhamento espiritual, referimo-nos aqui indistintamente a níveis de aconselhamento pastoral que podem ser muito diversos uns dos outros, quanto à modalidade de intervenção, aos destinatários, à figura do guia. Dentro dessa simplificação e em razão de minha específica (e por isso limitada) competência, escolhi privilegiar unilateralmente o aspecto relacional, e não os aspectos de conteúdo, intelectual $\mathrm{e}$, evidentemente, sobrenatural. Insisto, além disso, que com "atendimento psicológico" faço referência à psicoterapia psicanalítica, como aquela interessada em compreender em profundidade as raízes representacionais, motivacionais e relacionais do comportamento.

\section{Especificidades e interações}

A psicoterapia é uma relação funcional e temporária, livre, assimétrica (e não recíproca) que se instaura como resposta a um pedido de ajuda de uma pessoa que experimenta algum incômodo ligado aos próprios pensamentos, afetos e comportamentos perturbadores ou, em outros casos, que se sente interpelada por uma crise diante de novas tarefas ou de expectativas da sociedade circunstante, ou também apenas diante de interrogações acerca de sua identidade pessoal. Só para exemplificar, pense-se em como esse apelo para uma reestruturação do self se põe de forma dramática, às vezes com risco de patologias depressivas, no acesso de uma mulher à maternidade, especialmente se primípara.

A psicoterapia requer forte envolvimento pessoal, que encontra expressão numa comunicação verbal da parte do paciente, sem reservas preconceituosas ou censuras, direcionada a instaurar um melhor conhecimento de si, uma melhor competência dos próprios processos psíquicos, um amadurecimento das capacidades relacionais e, só consequiente e subordinadamente, a "cura" dos sintomas.

A investigação do incômodo atual conduz, inevitavelmente, a analisar a história pessoal do paciente, ao longo da qual os posicionamentos atuais vieram sendo estruturados. A história pessoal não é aqui entendida como a sucessão serial dos acontecimentos que tiveram lugar na vida do paciente, mas refere-se à modalidade com a qual ele os viveu, compreendeu, enquadrou, no interior de sua experiência de vida dentro de um discurso narrativo coerente, mas não necessariamente egossintônico, que estrutura sua identidade, por meio de crises e conflitos, às vezes com derivações patológicas. Porque a compreensão "i-mediata" de si do paciente não é necessariamente adequada a suas necessidades existenciais e a construção da identidade remete para uma matriz estrutural e relacional da pessoa humana. De resto, nem mesmo a compreensão que o terapeuta pode construir e eventualmente transmitir ao paciente esgota a riqueza das vivências (e menos ainda das vivências religiosas) e atinge a verdadeira "identidade" profunda do sujeito, que está sempre em devir e que o terapeuta só pode entrever por meio de sua própria mente representacional.

A personalidade do indivíduo é o resultado complexo e em processo de vir-a-ser de memórias compostas e estratificadas, que resulta de uma rede de relações (condições e condicionamentos) que fogem à consciência, que são inicialmente corpóreas e neurobiológicas (por exemplo, toda atividade mental tem um correspondente cerebral), hormonais (pense-se apenas na incidência do sexo biológico na percepção das diferenças de gênero), relacionais (o reconhecimento do outro e de suas expectativas funda a separação, a identidade e a diferenciação), histórico-epigenéticas (as experiências precedentes orientam e predispõem às experiências sucessivas), culturais (o modo e o grau de consciência de si do sujeito é também função do progresso dos estudos e do conhecimento deles) ${ }^{8}$.

Ora, a partir de uma descrição de algumas características da psicoterapia, gostaria de propor alguns temas de confronto entre a "cura" psicológica e o "cuidar" que sustenta também a intervenção do conselheiro espiritual.

Certamente, as finalidades das duas tipologias de intervenção sobre a experiência espiritual são diversas, embora ambas estejam voltadas para uma religiosidade que seja relação madura com um Deus significativo do ponto de vista psicodinâmico, vale dizer, com uma representação de Deus integrada e coerente com o conjunto do psiquismo do sujeito.

Mas o objetivo da psicoterapia é a libertação da personalidade in toto e o surgimento da verdade do sujeito. Para a intervenção psicológica, a vivência religiosa é um dos aspectos da personalidade, que deve ser harmonizado com os outros aspectos. E o amadurecimento do posicionamento em relação a Deus (na acepção "neutra", ou seja, no duplo sentido da aceitação de fé ou também da recusa) entre a tarefa mais vasta da formação de uma personalidade madura. Para a direção espiritual, o fim específico, e muitas vezes único, é o amadurecimento da fé do sujeito. Isso deveria comportar tanto uma fidelidade ao nível maturacional do indivíduo quanto a coerência com a concepção de Deus da religião de referência. Mas observe-se que, na direção espiritual, a tarefa de fazer amadurecer uma boa relação com Deus visa muitas

8 A propósito, é preciso denunciar o uso freqüentemente impróprio de expressões como "falta de identidade", "identidade frágil" e semelhantes. Para a psicologia, uma "pessoa sem identidade" é um oxímoro. A identidade é a pessoa, assim como de fato vive, com sua história e suas vicissitudes, por meio das condições e dos filtros da própria mente. Até a psicopatologia mais inclinada às classificações diagnósticas tem hoje dificuldade em usar semelhantes expressões que, ao contrário, derivam de fáceis simplificações (de conceitos psicológicos) caras à sociologia, quando não à literatura poética. Muitas vezes quem fala de falta de identidade parece referir-se seja a uma "norma" e, em última análise, a um modelo de pessoa assumido a priori de outra ciência (em particular a filosofia e a teologia), seja ao fracassado ou insuficiente percurso na consecução de tal ideal definido a priori. 
vezes um objetivo ou um percurso específico: o discernimento vocacional, a formação para a pastoral, etc., enquanto, por aquilo que me foi possível observar na realidade concreta da prática clínica com pessoas religiosas, a atenção à especificidade da relação com Deus, às vezes, deixa em segundo plano o contexto do crescimento pessoal.

Constatadas algumas diversidades nos objetivos entre acompanhamento espiritual e prática psicoterapêutica, o confronto pode ainda ser feito com utilidade nas modalidades relacionais, nos auxílios de comunicação, nas transformações interiores.

\section{Aspectos Psicodinâmicos da Relação de Ajuda: Traços para um Confronto}

De minha parte, a proposta de um confronto não pode articular-se a não ser como uma reflexão sobre alguns característicos processos psicodinâmicos a destacar na psicoterapia como acima definida, que sintetizarei em poucos pontos. Procurarei, em todo o caso, aqui e ali, fazer entrever, como em transparência, os possíveis reflexos nos percursos de direção espiritual.

\section{Relação funcional e temporária}

A relação de cura encontra sua justificativa na orientação a um escopo sobre o qual se constitui uma "aliança" terapêutica e uma espécie de "contrato"; em outras palavras, um final e uma finalidade. Contra isso se projetam alguns riscos, como os da interminabilidade, da infantilização e da "seqüela", pela qual o consultante se torna um sequaz e/ou o próprio consultor se compraz em ter um séqüito de filhos espirituais. Às vezes, acontece verificar-se a formação de grupos de sequazes ao redor de figuras carismáticas de guias (espirituais). Estes deveriam interrogar-se como tornar os próprios filhos espirituais "crentes adultos", independentes também deles próprios. A esperança de qualquer bom professor é que o discípulo, a quem ensinou a caminhar, possa andar longe e descobrir terras novas. Tarefa de qualquer bom professor (como de um bom analista) é encaminhar o aluno a andar com ele, mas também além dele, e não obstante ele. De resto, quantos diretores espirituais viram florir a santidade na vida de seus assistidos, discípulos que foram além das linhas de chegada que eles eram capazes de indicar.

A razão de ser da relação funcional psicoterapêutica, que pode ser muito profunda, é a busca do bem-estar do paciente. A consecução desse fim assinala também o fim da relação. E o fim é a finalidade da terapia: a deiscência do terapeuta, a diminuição de sua necessidade e, por conseguinte o seu afastamento para livrar o aluno de sua própria sombra. Creio que isso valha para qualquer processo de educação e formação e também para o acompanhamento espiritual. Dado por aceite que o amadurecimento da pessoa (e do cristão) segue uma linha assintótica, deve-se perguntar em que nível se dá o alcance da estatura adulta (cristã) na qual o sujeito se torna autônomo e, por sua vez, capaz e responsável pela formação de outros. Os filhos nascem, mas tornam-se adultos, genitores e mestres, por sua vez. Por essa característica temporária da experiência formativa, creio que se devam medir o conceito, o sentido e a eficácia da chamada formação permanente.

\section{Assimetria da relação}

A assimetria é conscientemente reconhecida e livremente aceita no que diz respeito à competência entre os dois. Isso não exime o consulente (embora parte mais "frágil") da própria responsabilidade sobre a correta gestão do processo relacional e sobre a tomada de decisões para a própria vida, embora a assimetria atribua maiores responsabilidades ao guia do processo relacional.

Como todas as relações assimétricas, a relação de ajuda está exposta ao risco da sedução e da perversão incestuosa. A sedução é um deslizamento de planos na dinâmica relacional, da assimetria da diversidade à simetria da complementaridade e à assimilação do outro a si mesmo (se-ducere). $\mathrm{O}$ bom professor, ao contrário, estimula no aluno o desejo da diversificação e da superação; indica uma estrada que ele percorreu de um certo modo e até um certo ponto, mas que não está nunca acabada, lançada em direção a uma meta nunca alcançada, aberta a possíveis novos percursos. O que ao professor se pede é que ensine a caminhar: transmitir um método, não fixar uma meta.

Uma outra anotação à margem pode dizer respeito à necessidade da livre escolha na determinação da oportunidade e da pessoa do parceiro na relação de ajuda. O terapeuta, em virtude também da assimetria da relação, tem a responsabilidade maior em aceitar ou recusar o paciente; e deve renunciar a trabalhar com pessoa com quem não se sinta em sintonia ou não se sinta em condição de condividir um percurso, necessariamente longo e exigente. A propósito, embora reconhecendo que muitos outros são os fatores em jogo no acompanhamento espiritual, poderia-se perguntar se o fator humano relacional pode ser negligenciado a propósito da escolha do diretor espiritual: pense-se, por exemplo, na situação de vínculo mais ou menos imposto com o diretor espiritual proposto ou preposto à comunidade religiosa, aos seminaristas, etc.

Certamente, menor é a responsabilidade dos dois parceiros, e talvez não predeterminável, quanto ao resultado do percurso de ajuda. Isso é motivo de contraste entre psicanalistas e ambientes médicos (e companhias de seguro!) que pretendem uma prognose e um cronograma dos resultados, para verificar a chamada eficácia da psicoterapia, ao passo que não se pode garantir uma cura definida e fixada preventivamente.

Da mesma forma, não se poderá garantir, por exemplo, no discernimento vocacional, o resultado do itinerário do seminarista. Certamente bom resultado de uma correta prática de discernimento poderia ser, também, o encaminhamento do seminarista por uma outra estrada, no caso que apareça chamado a responder a sua vocação cristã por vias diversas da do sacerdócio ordenado 9 . Isso comporta, em muito diretores perspicazes, a disponibilidade em acompanhar o jovem também depois de sua saída do seminário, naquele difícil momento de crise e de escolha de uma nova orientação de vida. E creio que, em toda plenitude, também essa tarefa mereça o nome de acompanhamento vocacional ${ }^{10}$.

9 Assim como, por exemplo, nas escolas de psicoterapia, o serviço formador do aluno está também em encaminhá-lo, se for o caso, a reconhecer nele uma impossibilidade ou uma contra-indicação ao trabalho terapêutico.

10 Felizmente passaram os tempos em que se ameaçavam castigos, temporários ou quiçá eternos, a quem era apressadamente identificado como "aquele que mete a mão no arado e olha para trás". Na prática clínica, tenho visto muito sofrimento em pessoas que de um dia para o outro se acharam nomeadas não mais como co-irmãos ou co-irmãs, mas como trânsfugas. 


\section{A exigência da abstinência}

A cura em seu conjunto e todo ato seu deve estar orientada para o bem-estar de quem pede ajuda e não para a gratificação pessoal de quem presta ajuda. Os desvios são possíveis por meio de uma multiplicidade de percursos nem sempre conscientes. Os processos de transferência e contratransferência, entendidos como reatualização inconsciente de processos psicodinâmicos importantes na história pessoal, podem ter nisso grande influência. Uma primeira verificação de uma correta posição da própria contratransferência poderia resultar da pergunta: o que digo/faço ajuda a mim ou ao paciente/consulente?

Um sacerdote, que tinha colóquios com uma jovem senhora, me contava: "depois de me ter dito essas coisas tão transtornantes a seu respeito, estava tão perturbada que senti que tinha necessidade de ternura e a abracei". Não nego as boas intenções e quiçá também, em algum (raríssimo) caso, a utilidade de gesto semelhante, embora me deixem em geral perplexo certas formas doentias, ou doentes, de contato no interior de uma relação de ajuda. Mas as perguntas a que aquele jovem padre teria devido responder, para melhor captar os significados de seu gesto, teriam podido ser deste teor: aquela "necessidade de ternura" era uma necessidade da senhora ou, antes, minha, ou de nós ambos? E, como necessidade, deveria ser satisfeita? Para qual benefício espiritual estava orientado meu comportamento? Porque tantas vezes sou eu que lhe telefono para perguntar-lhe como está e para oferecer-lhe uma conversa? Não me acontece um pouco demais de sentir a necessidade de contatos afetuosos com as jovens que vêm falar comigo? Que coisa isso quer dizer para a minha vida de consagrado?

$\mathrm{Na}$ realidade, creio que seja muito importante verificar com freqüência as próprias motivações, para evitar cumplicidades afetivas, relações muito mórbidas, envolvimentos e transtornos do próprio mundo afetivo e do mundo dos outros. Os psicanalistas o aprendem no curso de um longuíssimo período de formação, mediante a análise e a supervisão. E isso significa quanto seja delicada a situação. Estou convencido de que também as pessoas que oferecem acompanhamento espiritual deveriam ser preparadas com um bom conhecimento não só de si, mas também de si como sujeito de uma relação e, em geral, das próprias competências de comunicação. Daí nasce uma questão, que abro com interrogações: quem forma os formadores religiosos? De onde surgem os diretores espirituais dos seminários? Por meio de quais experiências, percursos, verificações de requisitos ou designações? Como floresce e amadurece a capacidade de maternidade-paternidade de um abade, de uma madre abadessa?

Da teoria e da praxe mais estritamente psicanalítica deriva um conceito ainda mais rigoroso de abstinência, que se refere a todo o conjunto do tratamento e comporta que a cura se funde na interpretação e não na satisfação das necessidades. Isso significa que nem sempre será procurada a satisfação do consulente, seu senso subjetivo de bem-estar, a gratificação emotiva ou sua consolação espiritual. De igual forma, deveria ser analisada e interpretada a gratificação do consultor ao constatar o próprio "sucesso": "Achou-se bem comigo... disse-me coisas que nunca tinha dito a nenhum outro", etc.

O clima emotivo (transferência/contratransferência), único - conditio sine qua non - a tornar possível a análise, não é a relação de simpatia, de facilitação da comunicação consciente entre paciente e analista. Supõe a reatualização de dinâmicas inconscientes que são investidas em novos objetos de afeto, in primis o analista. E isso se refere também às pulsões agressivas, destrutivas e autodestrutivas, e de certo não se reduz ao transporte erótico banalmente descrito como "enamorar-se do analista".

A transferência, de fato, é processo de "transferir", projeção de representações interiores sobre a figura do analista. Visa fornecer ao paciente, no analista, um lugar de projeção de suas vivências que, radicadas no passado, mas agora reatualizadas e postas em jogo poderão permitir, na análise, uma recontextualização dos afetos. Para melhor tornar possível a projeção, o analista procura não invadir o campo, ou melhor, "a tela de projeção" com suas pessoais vivências, juízos, comportamentos. Para isso, ele se faz pequeno, se subtrai à vista, não só física (pense-se no uso do divã), do paciente.

\section{A neutralidade}

A neutralidade consiste substancialmente num posicionamento disposto a reconhecer e não influenciar deliberadamente as opções de valor e os comportamentos conseqüentes da pessoa. Caracteriza a psicoterapia profunda em comparação com intervenções mais sugestivas.

A neutralidade analítica foi representada por Freud com metáforas lamentavelmente infelizes que passam uma imagem de distanciamento e frieza (cirurgião, espelho, telefone), que depois foram retomadas por alguns discípulos de maneira literal e rígida, a ponto de desnaturar-lhe o sentido ${ }^{11}$. Mas, na esteira de numerosas indicações do próprio Freud, sabemos que a neutralidade não constitui o analista como frio espelho. Na realidade, o processo de transferência não acontece num âmbito de esterilização dos afetos do analista, mas só no quadro do respeito e da predominância das vivências do analisando. As reações emotivas pessoais do analista não podem ser negadas, mas não devem invadir o campo terapêutico da relação dual.

A aplicação da neutralidade no âmbito da direção espiritual coloca problemas práticos e questões teóricas, entre os pólos do respeito dos ritmos de crescimento espiritual da pessoa e as metas e percursos (às vezes institucionais) que se lhe pretende propor. Outras dificuldades derivam das relações entre "foro interno" e "foro externo", que vêem muitas vezes prevalecer as instâncias do primeiro. Deixo, porém, a outras competências as considerações sobre a aplicabilidade, no acompanhamento espiritual, de certos aspectos da neutralidade, que descrevo a seguir da forma como são requeridas na correta prática clínica.

a) Aceitar a incompletude e o gradualismo, intrínsecos a qualquer relação de crescimento humano, assim como a nãolinearidade do percurso; regressões, avanços desarmônicos, não sincrônicos.

Na direção espiritual, isso deverá confrontar-se e harmonizar-se com a proposta de desempenhos de crescimento.

11 O próprio Freud se queixava disso numa carta ao pastor Pfister, de 22 de outubro de 1927: "O senhor sabe da inclinação das pessoas a tomarem prescrições literalmente ou exagerá-las. Isso fazem, como bem sei, alguns dos meus alunos em relação à passividade analítica" (Freud \& Meng, 1927/2001, p. 150). 
Talvez pudesse ser procurada uma “discrepância ótima” entre o estado atual e a meta proposta. Esse critério se propõe, na prática, a pedir ao crescimento do sujeito sempre o passo mais comprido possível. Os dois termos do confronto ("mais comprido" e "possível") devem ser entendidos em posição dialética: sem perder de vista a meta, mas sem negligenciar as características e possibilidades do sujeito. A sabedoria pastoral sabe graduar esse princípio e, ao mesmo tempo, colher o sentido dos momentos e das etapas internas ao percurso da pessoa, medindo-os segundo o nível de maturidade e de crescimento do sujeito e de sua fé, numa ótica genética do vir-a-ser religioso que veja a maturidade como um projeto jamais completado, que se realiza segundo os parâmetros da processualidade e da perfectibilidade.

b) Faz parte da neutralidade também saber escutar. Muitas vezes indo além das palavras, para colher a verdade do não-dito, na não-verdade do dito; a "talking cure", de que fala Freud, é análise do discurso, mas também das lacunas do discurso: os esquecimentos, as preterições, as redundâncias...

Saber escutar significa não só saber colher o incômodo, mas também deixar que ele se expresse nas palavras do paciente, em seu próprio formular-se, no processo em que o sofrimento se torna palavra, evitando o recurso fácil a formas de silenciamento do sujeito. Esse risco pode ser verificado, como já observei, em algumas formas de intervenção psiquiátrica, quando a prescrição de fármacos adquire uma função anestésica do sintoma. Isso pode significar tolher ao paciente a voz que se exprime no sintoma, em vez de compreendêlo. E não se pode esquecer que também a prescrição de um fármaco estabelece modalidades relacionais e coloca-se em um contexto relacional ${ }^{12}$.

No que diz respeito ao paciente, a tomada do fármaco fora do contexto relacional veicula, muitas vezes, uma visão do distúrbio psíquico como parte separada do self, a ser gerida com uma intervenção pontual e fragmentária. E a esse propósito me permito só um aceno ao fato de que, em pessoas e comunidades religiosas, se encontra um discreto uso de psicofármacos, e assinalo que o efeito ansiolítico do fármaco pode, às vezes, ser procurado também no álcool ou em outras formas de desordens e de esquisitices.

c) Saber escutar quer dizer também abster-se da gratificação de tipo voyeurístico. O que se quer obter é um conhecimento em função do consulente, não a saciação de uma inútil ou perversa curiosidade. A psicanálise evita isso abstendo-se quanto possível de fazer perguntas e forçar confidências; na confiança de que o que é verdadeiramente relevante surgirá no curso das associações livres do paciente ou, em todo caso, em seu contar-se. As revelações forçadas ou muito profundamente escavadas, inclusive pelo próprio sujeito, de coisas há muito tempo conservadas em segredo, têm um significado psíquico e relacional que deve ser indagado. Se há silêncio, se o paciente não consegue contar para si mesmo aspectos ou episódios da própria vida, significa que não está pronto para agüentar a visão deles, que o sofrimento (às vezes, o distúrbio psíquico) que daí resultaria é muito forte.

Com freqüência também o esforço de sinceridade autoimposto, até mesmo o bem-estar aparentemente derivado de uma confissão penosa pode, em seguida, fazer uma re-

12 Para um aprofundamento, permito-me remeter a Aletti (1998). viravolta, como dificuldade no prosseguimento da relação terapêutica (ou espiritual).

Uma pessoa idosa, mulher de mais de 80 anos, consumiu todo o tempo da primeira sessão em contar-me, com aparente senso de libertação, alguns episódios de uma vida sexual marcada pela masturbação que persistia atualmente e era investida de gravíssimos sentimentos de culpa, com angústias de perdição eterna. Interpunha entre as narrativas dos episódios freqüentes expressões do tipo "Isso nunca contei a ninguém, nem mesmo na confissão", nas quais não era difícil ler tentativa de sedução em relação a mim ("olhe que privilégio lhe concedo"). Mas, em contraste com esse aluvião de revelações íntimas, no curso da sessão sucessiva me comunicou sentir-se "violentada" de minha parte pelo fato de que eu a teria induzido a abrir-se a certas confidências que ela, vindo ao atendimento, tinha decidido não revelar.

Para o terapeuta, assim como para o conselheiro espiritual, existe também o risco de uma espécie de voyeurismo, que chamaria da "vida vivida por procuração". Às vezes, pessoas que vivem em alguma forma de solidão (social, afetiva ou, quiçá, também física) encontram uma espécie de compensação em participar, também emotivamente, nas vicissitudes, inclusive mais íntimas, dos outros e em seus movimentos interiores.

d) Saber escutar quer dizer também saber esperar. Esperar que a verdade do sujeito se instaure nele mediante o seu contar-se. Não antepor a própria palavra à do paciente, deixando-lhe a possibilidade e o tempo de falar, de escutar-se e de reencontrar-se em sua própria narrativa, de dar expressão a estados de alma que ainda não tinham encontrado o caminho. Nem mestre, nem médico da alma, o analista não tem o poder da cura, nem o do desvelamento; mas tem a competência de ser testemunha e hermeneuta da autenticidade do sujeito. Esse saber esperar que apareça a verdade vale também para o paciente em relação a si mesmo, sem velozes corridas à frente e escolhas não amadurecidas gradualmente no curso do tempo. Em muitos casos, a capacidade, da parte do terapeuta, de tolerar a incerteza e o indefinido se comunica, positivamente, também ao paciente.

e) Encontrar as palavras para escutar é uma outra das declinações possíveis do saber escutar. Muitos aparentes entendimentos ou cumplicidades com o paciente, que começam com um "compreendi perfeitamente", "já enquadrei seu caso", "é um caso clássico; vejo muitos como o Sr." ou também "não deve preocupar-se, são coisas que acontecem a todos", que querem ser tranqüilizadoras, são muitas vezes, na realidade, perturbadoras: tiram do sujeito a possibilidade de falar, de escutar-se em sua própria narrativa, ou chegam mesmo a comunicar "você é um 'caso' como tantos outros" e desencorajam a possibilidade de sentir-se protagonista do próprio percurso. De fato, transmitem a mensagem: "eu posso ser de ajuda para você, porque eu lhe dou minha competência; eu o curo". E não, ao contrário, "coloco-me a seu serviço para que você possa ver a solução de seus problemas, a resposta a suas interrogações, a possibilidade de sua resposta ao apelo de um Deus que chama você pelo nome". Uma intervenção do diretor espiritual que seja animado pela esperança de que Deus se manifesta e apela à pessoa por meio da relação instrumental com o "pai” espiritual, estará sempre menos preocupado em "ajudar" e "acelerar" o crescimento 
mediante os conteúdos das exortações, das prescrições, das proibições, das opções guiadas.

f) Acerca das relações entre percurso terapêutico e adesão de fé, a experiência clínica mostra que uma abordagem fincada na neutralidade pode ajudar as pessoas a aprofundar as razões de sua fé e de sua adesão. Ao mesmo tempo pode ajudar outras a libertar-se de resíduos patológicos de sua religiosidade. O problema da perseverança na fé é, ao contrário, conexo com a própria fé. Nenhuma psicoterapia faz "perder a fé". Uma fé que cai por causa de uma psicoterapia é um fiapo de fé, que não se sustenta ao confronto crítico e à consciência do sujeito.

Em conseqüência, para uma boa psicoterapia não é necessário que o psicólogo seja crente. Basta que seja um bom psicólogo, isto é, que saiba manter a própria neutralidade e abstinência. Ao contrário, eu creio que a expressão "psicólogo católico" tenha sentido só se revirada em "católico psicólogo", enquanto o adjetivo "católico" não acrescenta nada à especificidade profissional.

Quando um paciente religioso praticante me pergunta "Antes de iniciar a terapia quero saber se o Sr. tem fe",, anoto mentalmente que tem, além de uma certa desconfiança em minha competência profissional, alguma resistência em analisar algum material de sua psique e, provavelmente, se sente inseguro acerca de sua própria fé. Do mesmo modo que a senhora que começa dizendo "Podemos falar de tudo, mas não tenho a intenção de discutir meu casamento", com boa probabilidade está comunicando que seu casamento está em crise.

Um aspecto mais crítico da neutralidade se manifesta quando são mais radicais as alternativas entre a tarefa educativa e a liberdade a deixar ao educando. Cito um caso em que talvez seja mais evidente a diferença de posição entre o psicanalista e o diretor espiritual e o retiro, ainda uma vez, de Winnicott que, com seu eficaz e personalíssimo estilo paradoxal, sublinhava que uma educação religiosa verdadeiramente libertadora deveria colocar o indivíduo em condição de libertar-se também dos nós que podem ter-se constituído pelas próprias formas religiosas institucionais. De sua própria experiência pessoal, ele, não crente, dizia: "Sempre fiquei muito contente com o fato de que minha educação religiosa tenha permitido que eu me desenvolvesse em outras direções" (Winnicott, 1996, p. 111s), em relação à religião. Aqui, a neutralidade se apóia na confiança nos percursos do homem e na espera. Mas até que ponto semelhante posicionamento poderá ser assumido por um diretor ou acompanhante espiritual $?^{13}$

Na realidade, a neutralidade não é especificamente requerida, antes, é por muitos lamentada no diretor espiritual. Este condivide a mesma fé com quem lhe pede ajuda, é desejável que tenha feito nela um longo percurso e é considerado mestre e exemplo na fé. Além disso, a direção espiritual é também função da experiência e do crescimento espiritual do diretor, de sua maturidade religiosa, de sua experiência pessoal de Deus, de sua capacidade de ser mediação e "figura" do amor de Deus. É preciso sublinhar que a troca da conversação, a proposta de metas, a indicação de modelos é realizada principalmente no nível do "consciente". Mas é, de qualquer forma, importante que o diretor esteja consciente de quanto acontece nele, mediante ele, e também, sem que ele o saiba, através das dinâmicas inconscientes, representacionais e transferenciais/contratransferenciais.

As motivações, os afetos e os aspectos relacionais inconscientes agem tanto na direção espiritual quanto na psicanálise, porque agem em qualquer relação humana, como húmus da troca verbal. A questão decisiva está em se estar disso consciente e na utilização que disso se faz. A psicoterapia, em especial a psicanalítica, faz da exploração e interpretação da transferência e dos desejos inconscientes, o lugar para uma reestruturação de toda a vida afetiva, enquanto o acompanhamento espiritual visa um amadurecimento da relação com Deus, apoiando-se na clarificação consciente e no empenho da vontade, além de, certamente, na graça.

Esses diversos horizontes conceituais e metodológicos apontam que situações complexas são aquelas de uma psicoterapia de uma pessoa religiosa, da psicoterapia exercida por um religioso, do acompanhamento espiritual de um psicoterapeuta.

\section{Referências}

Aletti, M., Fagnani, D. \& Rossi, G. (2006). Religione: cultura, mente e cervello. Nuove prospettive in psicologia della religione. Turim: Centro Scientifico Editore.

Aletti, M. (1998). Per una lettura psicoanalitica del símbolo religioso. Em D. Fagnani \& M. T. Rossi (Orgs.), Simbolo, metafora, invocazione: Tra religione e psicoanalisi (pp. 13-45). Bergamo: Moretti \& Vitali.

Freud, S. (1996). Novas Conferências Introdutórias sobre Psicanálise e Outros Trabalho (J. L.Meurer, Trad.). Vol. XXII (pp. 63-84). Rio de Janeiro: Imago. (Trabalho original publicado em 1932)

Freud, E. L. \& Meng. H (Orgs.) (2001). Cartas entre Freud e Pfister (1909-1939). Um diálogo entre a psicanálise e a fé cristã. (K. H. K. Wondracek e D. Junge, Trads.). Viçosa: Ultimato. (Trabalho original publicado em 1963)

Godin, A. (1987). Ascolto e consiglio. Em B. Lauret, F. Refoulé \& E. Costa, Jr. (Orgs.), Iniziazione alla pratica della teologia, vol. 5 (pp. 48-78). Brescia: Queriniana.

Rizzuto, A-M. (1979). The birth of the living God. A psychoanalytic study. Chicago: The University of Chicago Press.

Seveso, B. (2003). Pastorale e psicologia. Teologia, 28(3), 305-334.

Vergote, A. (2006). Le père. Familia, 33, 5-21.

Winnicott, D. W. (1996/1968) Tudo começa em casa (pp. 111-116) (P. Sander, Trad.). São Paulo: Martins Fontes.

Recebido em 06.10.2007

Primeira decisão editorial em 14.10.2007

Versão final em 20.11.2007

Aceito em 15.12.2007

13 Creio que questão semelhante se coloque também acerca do posicionamento adequado da parte de um sacerdote-psicoterapeuta (e talvez aponte as aporias do duplo papel), quando a exigência de neutralidade do psicoterapeuta se desencontra com importantes convicções e irrenunciáveis valores pessoais. 